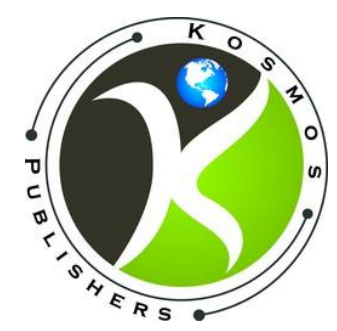

\title{
Health Promotion Program via Social Media for Hypertension and Diabetes Mellitus Patients
}

\author{
Prasak Santiparp*
}

Mahidol University, Thailand

\begin{abstract}
Received Date: September 10, 2021; Accepted Date: September 21, 2021; Published Date: September 29, 2021;
*Corresponding author: Prasak Santiparp, Faculty of Social Sciences and Humanities, Mahidol University, Thailand. Email: zakpeace7052@gmail.com
\end{abstract}

\section{Abstract}

To date, hypertension and diabetes mellitus are serious health problems because advance technology has led to consumerism of lifestyle transformation especially mobile smartphone. Social media is very popular now, so health promotion program via social media is interesting. The aims of this study were to synthesize and analyze the results of health promotion program via social media. It was divided into two phases; phase 1) the program development by literature reviewing was performed. Phase 2) quasi-experimental research (one group, pre-test and post-test) was conducted. The 31 volunteers were included in this program with 5 days by face to face meetings and further 28 days via social media. The finding showed that health literacy, attitude and self-care behaviors of participants were improved significantly by sign test ( $p$-value < 0.01 ) before and after program implementation. The suggestion is health promoting program via social media with the principles of transformative learning used to raise awareness, change attitude and behavior to good behavior in lifestyle diseases should be considered.

Keywords: Diabetes Mellitus; Health Promotion; Hypertension; Social Media

\section{Background and Rationale}

Nowadays, hypertension (HT) and diabetes mellitus (DM) are the most prevalence of chronic conditions. The complications from cardiovascular disease (CVD) of HT. and DM. led to high morbidity and mortality (Yu, Suissa, 2016, Yach, Leeder, Bell, Kistnasamy, 2005). According to the World Health Organization (WHO), HT and DM are major therapeutic concerns globally. In 2018, the World Health Organization estimated that CVD and DM were the first and seventh leading causes of deaths respectively (WHO, 2018). Evidence indicates that controlling blood pressures, plasma glucose levels and CVD risk factors can protect or extend one third mortality from CVD (DeFronzo, 2010).From the Thai National Health Examination Survey (NHES) during 2014 - 2019, data demonstrated that HT and DM affected nearly $20 \%$ of Thai adults' health problems (Aekplakorn, et.al., 2020). In 2019, HT and DM constituted of 1,468,433 and 941,226 persons or 2,245.09 and 1,439.04 per 100,000 Population respectively, accounted for outcome lost about 59,670 million bahts (Ministry of Public Health Thailand, 2020). Currently, the identification and prevention risk factors of HT, DM and CVD are focused in health promotion program. Patient engagement is critical to successfully controlling HT, DM and thereby reducing morbidity and mortality (Riegel, et al., 2017). One of the ways to reduce these burdens is promoting self-care in HT and DM patients. Self-care has been described as an important component in HT, DM and CVD prevention and management (Beck, et al., 2017). There was a few understanding of the sustainability of self-care behavioral, psychological and social processes. Self-care for HT and DM was a complex, multifactorial endeavor with few effective intervention strategies to help patients manage their conditions (Grady \& Gough, 2014). Medical doctors always spend very short time with their patients. Hence, patients need to independently skills, knowledge, and motivation to increase personal results. Many studies of multiple self-care trials showed that lifestyle modification programs were better than usual care in improving clinical results for HT, DM and CVD (Alharbi, Gallagher, Kirkness, Sibbritt, Tofler, 2016). Despite the known benefits, patients face many obstacles in meeting the necessary lifestyle transformations involved in self-care such as poor selfefficacy, and cognitive decline. It may not be surprising that in an era when resources for health promotion are limited and the 
expectations as to what can be achieved are high, that 'sustainability' has become a familiar catch-cry (Riegel, et.al., 2017). The objective of health promotion is to make program effects that may be sustain over time. Risk factors and preventive complication interventions are not only conceptualized at the individual levels, but organization or social organization also (Swerisssen \&Crisp, 2004). So the appropriateness of an intervention for HT and DM aimed at enhancing sense of self, health, self-care agency and personal control. The studies have documented the significant role which patient's mindset (or attitude toward health, life, self) played in determining successful self-care management of HT and DM. The patient's negative mindset interacted dynamically with support systems to create unsuccessful dependence, with frequent readmissions to hospitals. The potential for enhancing patient's mindset and, in turn, participation in one own health and health promotion intervention through application of perspective transformation was thereby identified. The less negative mindset and opposition of self-care program, the more sustainability. (McWilliam et.al., 1999; Peters \& Keeley, 2017). The learning process to change attitude is transformative learning theory. It is defined as condition of being human. It is that we have to understand the meanings of our experiences. For some, any uncritically assimilated explanation by authority figure will suffice. But in contemporary societies we must learn to make own interpretations rather than act on the purposes, judgments, beliefs, and feelings of others. It develops autonomous thinking (Mezirow, 1991). Hence, selfcare promoting program, which encourage motivation or change attitude, is very interesting.

The markedly risen utilizations of smart phones are now frequently employed with lifestyle programs to promote prevention, management and self-care behaviors of HT and DM (Santarossa, Kane, Senn, Woodruff, 2018). Peer-to-peer engagement, which is communicating with other people experiencing the same chronic condition to learn more about controlling and managing their conditions, was found helpful to overcome some of obstacles and has been found to facilitate self-care, resulting in improved health behaviors (Lauckner, Hutchinson, 2016; Fisher, et.al., 2017). Social media application offers a convenient venue that is easily accessible for addressing patients' educational needs and providing realtime interaction with others who share many of the challenges in disease management (Roblin, 2011). Social media users have recognized the potential for providing support to others who are managing chronic conditions (Partridge, et al., 2017; Alharbi, Gallagher, Kirkness, Sibbritt, Tofler, 2016). Many studies found adding usual health care services using social media platforms can satisfy patients' social support needs with managing their conditions (Smailhodzic, Hooijsma, Boonstra, Langley, 2016). Therefore, leveraging social media may be a viable strategy to help improve self-care for HT and DM.

\section{Objectives}

- To develop a health promotion program via social media for hypertension and diabetes mellitus patients.

- To study the results of health promotion program via social media for hypertension and diabetes mellitus patients.

\section{Materials and Methods}

This study was divided into two phases. Phase 1 was literature reviewing. Phase 2 was quasi-experiment study. For phase1, the investigator developed health promotion program via social media and synthesized the activities or interventions for phase 2. Phase 2 was compared health literacy, attitude, and self-care practices before and after program attendance for 33 days. The main intervention premised upon transformative learning. Through participation in reflection, the individual was intended to acquire an understanding which altered their expectations, beliefs, values and perceptions related their experience of chronic illness. The phrases of perspective transformation vary with the topic reflected a self-caring and therapeutic application intended to transpire over the course of self-care. The evaluation was measured health literacy, attitude and self-care practices by personal assessment questionnaires which already tested for validity and reliability by specialist validation (IOC value more than 0.5 ), internal consistency (Chronbach's alpha; 0.78 and 0.81 for attitude and self-care practice) and KR-21 $(0.79,0.75,0.78$ for functional, inter-relationship, critical health literacy) for reliability. Data were analyzed using t-tested and sign tested comparing between pre and post intervention. Exclusion criteria eliminated those who were cognitive impaired or pregnancy. The sample size was calculated to compare the differences in mean change scores on the selected outcome measures of mindset for a medium effect size of 0.80 with alpha set at 0.05 (two-tailed) and beta set at 0.20 was 31 participants.

\section{Results}

The result of phase1 demonstrates that transformative learning is a change in perspective, meaning or attitude through a process of reflection and critical thinking. These changes result in the acquisition of new perspectives, attitudes, and behaviors that are integrated into new roles and relationships as these changes integrate with one's own life. Mezirow's theory of transformative learning may not be a complete theory of adult development. Therefore, other theories about changing attitudes should be considered. In addition, transformative learning focuses on personal change and use negative processes Therefore, it should be integrated with other concepts, theories or attitude change principles to achieve positive change at the family, community, organization, society and process level (Dirkx, 2006). The process of transformative learning takes place through the reflection of the individual with the reflection of critical thinking (contemplation of conversation by reflecting on important ideas, both emotional and rational) (Mezirow, 2000).

The ten-step process of Mezirow's transformative learning, in which these stages are experienced through a variety of events, can be of varying intensity, including: 1) disoriented dilemma; 2) self-examination with feelings of fear, anger, guilt, or embarrassment 3) assessment of assumptions and important relationships 4) perceptions of others' dissatisfaction and the process of change is shared with others. 5) exploring options for new roles, relationships, and actions 6) temporary efforts in new roles 7) building competence/ confidence in new roles and relationships 8) planning of actions acquiring knowledge and skills for implementation of 
the plan 9) acquiring knowledge and skills in implementing the plan 10) returning to one's life on the basis of conditions stipulated by one's new perspective. The basis of transformative learning is experience and epistemological perception. Epistemology of transformative learning is a rational cognitive process that results in a real change in attitude if that cognitive process affects the change in the nature of one's perception that occurs. Reflection with reasons and emotions is the process of critical reflection (Antonacopoulou \& Gabriel, 2001).

Mezirow did not focusing on personal factors affecting the socio-cultural. The learner's context influenced the learner's perception of meaning and the attitude change process. There was a fragmentation of the influence of sociocultural discourse and history that might cause imbalances in the complete dimension of learning for social change (Taylor, 1993; 1998). Merriam (2004) described that even transformative learning led to a more mature, liberal and developed level of thinking, Mezirow did not mention that a certain level of cognitive development was required before transformative learning could be achieved actionable. Learners and critical reflection conversations must enable learners to assess critical experiences. Attitudes were deeply established during these periods by asking basic questions and rearranging attitudes, for example, asking how they act and think, for example, but not all learners were ready to do this. Convenience must prepare these learners first. Fook \& Askeland (2007) reported that research experiences in transformative learning subjects significantly altered a person's attitudes with knowledge, understanding, or learning related to emotion and spirituality has been important. Lange (2004) reported that transformative learning was largely the result of storytelling. Participants used metaphors to describe their experiences. The process of learning for transformation was both emotional and rational in conjunction with external events. This enabled the process of learning for change to successfully change attitudes. Tenant (1991) told that while a change of perspective could lead to intellectual development, it has been not always lead to psychological development. Teachers or facilitators need to be careful about putting too much expectations on students. Illeris (2004) said that theory of transformative learning should encompass much more about the knowledge, understanding, emotions and environment that reflect all individuals in society. Wasserman (2009) found that critical reflection through storytelling and dialogue could foster transformative learning and changed attitudes. O'Sullivan (1999) found that experiences related to transformative learning included emotional, intellectual, spiritual, perceptual, and cognitive learning could change attitude. Harvie (2004) explained that Mezirow's theory of transformative learning problems, according to Taylor opinions, have become the basis of academic critique of Mezirow's theory of transformative learning over the years and improving learning for better change. Merriam (2004) indicated that only some adult learners were in the right phase of cognitive development for transformative learning. This might explain why many learners fail to successfully implement Mezirow's 10 steps of transformative learning. Dirkx (1998) explained that Mezirow was criticized for not including the whole person or society. The decision-making process of learning for change was only at the individual level. The link between critical reflection and action created a theory of learning, which was operational learning, which was learning from practice. The learner or the participant must engage in complex real problems by questioning existing knowledge. Reflection of thoughts was on actions before, during and after troubleshooting. The goals of operational learning and action were determined by the organization or society, and individual change, which must be directed towards achieving those goals of the organization or societies where an organizational focus on learning can be the basis for personal change. Cranton (1996) demonstrated that by using Jung's basic personality, along with the use of concepts, feelings, and instincts, personality development could be developed. Personality could influence personal learning styles. These were summarized as components of transformative learning as: 1) perceived values and attitudes 2) sensitivity to events 3) questioning values and attitudes 4) reflections of content and processes 5) reflections of context 6) rational discourse 7) evaluation of values and attitudes 8) correction of attitudes or semantic perspectives. Although each personality type tended to play a part in certain elements but not in all components, but it could make transformative learning happen. Therefore, the process of transformative learning was different for each adult learner. Finding out the personality type of learners would help promote transformative learning differentiate each learner. Boyd \& Meyers (1988) determined transformative learning from the perspective of psychology that it was a fundamental change in personality as a result of the resolution of personal problems. The consciousness fostered the formation of personality as a result of internal conflicts. The entire process of a person was person-centered, including the ego and the unconscious. Transformative learning was a process of reflection and critical thinking or critical reflection in listening. Recognizing the need for choice, confrontation, and compromise with sorrow, so change is the transfer between person from personality to spirit. While Mezirow's transformation is personal change. Ego was important. Dirkx (2000; 2001) demonstrated that looking at the picture behind the psychology drives emotion, feelings and behaviors ultimately provided a framework for change. Readying to create the idea that emotional experience was the link between mindfulness and activation of experience. Transformative was about emotions, sounds, or images that convey a profound inner life that could not be controlled by a strong connection with reason. Natural imagery was the path to the unconscious self. These images connected the inner and outer self through emotion and helped create the meaning of the world. These images were linked to our initial meaning creation and created through imagination, which encouraged us to ask ourselves as we learn: What emotions were we experiencing that remind us of the past? When did we first feel these emotions? What happened and what was involved? Asking these questions created a picture that connected these emotions to experiences. Strategies for using these images in a positive and dynamic manner by describing them as clearly as possible as well as connecting images with other aspects of our lives or magnify images through stories, poems, fairy tales or legends, creating animations must be allowed to talk or interact through imagination or have more imagination. Cranton (2006) described that critical reflection consisted of content, process and premise reflection. Lytle (1989) showed that a study of Mezirow's 10-step process with a semi-structured interview 
form found that only 30 percent of nursing students experienced all Mezirow's 10 steps. All participants experienced only the first four steps. Taylor (2003) found that while transformative learning theory was widely applied in a wide variety of situations, very little research has provided support for Mezirow's comprehensive model. Much of the existing research focused on the theoretical part of critical reflection that changed context or perspective and also found that most of the research was retrospective based on critical reflections of past experiences and based on the participants' desired vision or attitude, which may not be entirely accurate. Cesar (2003) found that only 40 percent of his participants experienced all Mezirow's 10 stages and found that consensus was low in the early stages of transformative learning. Of the study participants, 97 percent experienced steps one to three, and 93 percent experienced steps one to four, and 73 percent experienced steps one to five. Participate in fewer studies experienced the sixth to tenth steps. Social change is the result of individual-level changes that occur in the relationships of individuals in society. Scott (2003) described that social and personal change would occur simultaneously with the interdependence between organizational change and individual change. Learning for each step of change might be the result of participating in organizational development initiatives.

Taylor (2009) demonstrated that 6 core elements for transformative learning comprised of experience, critical reflection, dialogue, holistic orientation, awareness of context, and an authentic relationship and practice. Individual experience, the primary medium of transformative learning, consisted of what each learner brings (prior experiences) and also what he or she experienced within the classroom itself. Critical reflection, a distinguishing characteristic of adult learning, referred to questioning the integrity of deeply held assumptions and beliefs based on prior experience. It was prompted in response to an awareness of conflicting thoughts, feelings, and actions and at times could lead to a perspective transformation. Dialogue was the essential medium through which transformation was promoted and developed. However, in contrast to everyday discussions, it was used in transformative learning "when we have reason to question the comprehensibility, truth, appropriateness (in relation to norms), or authenticity (in relation to feelings) of what was being asserted or to question the credibility of the person making the statement". The holistic orientation encourages the engagement with other ways of knowing-the affective and relational. Past research had demonstrated that too much emphasis was given to rational discourse and critical reflection in fostering of transformative learning and not enough recognition of the role of the affective and other ways of knowing. Developing an awareness of context when fostering transformative learning was developing a deeper appreciation and understanding of the personal and socio-cultural factors that played an influencing role in the process of transformative learning. These factors included the surroundings of the immediate learning event, the personal and professional situation of the learners at the time (their prior experience), and the background context that was shaping society. Environmentally one of the most significant contextual issues of transformative learning was temporal constraints. Research had suggested that fostering transformative learning was timeconsuming, particularly when an effort was being made to provide access to all participants' voices as well as coming to consensus around various group decisions. Furthermore, working with rigid time period posed additional challenges when engaging intense personal experienced that could not be resolved by the time class was over. These efforts were further compromised with a traditional classroom setting with short class period. A sixth element was the importance of establishing authentic relationship. Fostering transformative learning in the classroom depended to a large extent on establishing meaningful, genuine relationship. Previous research found that establishing positive and productive relationships with others was one of the essential factors in a transformative experience.

In conclusion, transformative learning is not necessary including all 10 steps of Mezirow's theory. the main steps of transformative learning are disoriented dilemma, critical reflection on self-examination with reasons and feelings of fear, anger, guilt, or embarrassment, assessment of assumptions and important relationships, perceptions of others' dissatisfaction and the process of change is shared with others new roles, dialogue or discourse in content, process and premise reflection, propose and accept new perspective to change personal, organizational and social perspective. This synthesized transformative learning process based on experience, holistic orientation, awareness of context and authentic relationship and practice. The appreciative inquiry is suitable applied for premise reflection, organizational with social transformation perspective and fostering perspective transformation.

Appreciative inquiry offers a positive way to explore, discover possibilities, and transform systems and teams in the organization toward a shared vision (Cooperrider \& Whitney, 2000). Appreciative inquiry adopts a social constructionist view and based on the principles of positive dialogue and collaboration, appreciative inquiry has been reported to be useful in supporting change in self-care practice (Scerri, Innes, $\&$ Scerri, 2019). Tapping into the motivations for change by using a positive approach can unlock the collective intelligence and build group capacity (Hung, et al., 2017). Aligned with critical social theory that is the basis of transformative learning, appreciative inquiry supports an egalitarian form of open dialogue. By challenging the dominant hierarchical power relation, appreciative inquiry empowers practitioners to become change agents and to explore innovative practice. People at the point of care are encouraged to engage in practice development project to improve the behavior and move toward shared visions for a better future (Trajkovski, et al., 2015). Bringing persons together to cocreate change not only creates means for socially reinforcing change but also increases the potential for a larger impact (Willis et al., 2016). Unlike the punitive style of performance management, appreciative inquiry supports learning and reflection in a positive way (Curtis et al., 2017). The convergence of transformative learning and appreciative inquiry provides such a foundation. Possibilities for joining these theoretical perspectives and practices, and the potential impact of their synergy, will be illustrated through discussion of a new bridging construct, appreciative transformative learning, which builds strength from the union of transformative learning and appreciative inquiry in fostering deep and lasting change. From point of view, change of this nature begins at the individual level and then expands to the group as a direct 
outcome of individual and collective transformative learning. To result in new behaviors at the organizational level, this change must be embedded in the cognition, memory, and perspective of individuals and the whole. Others have identified this process as collective or organizational learning (Yorks \& Kasl, 2002).

In conclusion, the main steps are disoriented dilemma, critical reflection by dialogue or discourse in content, process and premise reflection propose and accept new perspective. The premise reflection and propose and accept new perspective to change personal, organizational and social transformation perspective consisted of discover, dream, design and destiny. This synthesized transformative learning process based on experience, holistic orientation, awareness of context and authentic relationship and practice.

The synthesized intervention contained disoriented dilemma, critical reflection in content, process and premise reflection, propose and accept new perspective by discover, dream, design and destiny. The intervention consisted of faceto-face for 5 days and online utilized LINE application for 28 days. The evaluation of intervention demonstrates that the participants were 25 women $(80.6 \%)$ and 6 men $(19.4 \%)$, the average age was 67.5 years old. All of them were Buddhists. The highest education levels of participants were $22(71.0 \%)$ participants in primary school, $6(19.3 \%)$ participants in secondary school and $3(9.7 \%)$ participants in university. Most of them (22 or $71 \%$ ) had income that were not enough for expenses. The occupations were housewife (19 or $61.3 \%$ ), work for hire (5 or $16.1 \%$ ), government officer (4 or $12.9 \%$ ) and merchant ( 3 or $9.7 \%$ ).

Comparison of health literacy before and after participating in the program found that the participants in the program had better health literacy at all three levels, as shown in Table 1.

\begin{tabular}{|c|c|c|c|c|c|c|}
\hline \multirow{2}{*}{ Health Literacy } & \multicolumn{2}{|c|}{$\begin{array}{c}\text { Prior joining } \\
\text { Program }\end{array}$} & \multicolumn{2}{c|}{$\begin{array}{c}\text { After joining } \\
\text { Program }\end{array}$} & \multirow{2}{*}{ t-test } & \multirow{2}{*}{ p-value } \\
\cline { 2 - 5 } & Mean & SD & Mean & SD & & \\
\hline $\begin{array}{c}\text { Functional health } \\
\text { literacy }\end{array}$ & 11.5 & 3.7 & 18.1 & 2.6 & 22.8 & $<0.001$ \\
\hline $\begin{array}{c}\text { Inter-relation health } \\
\text { literacy }\end{array}$ & 14.2 & 3.3 & 20.1 & 3 & 15.8 & $<0.001$ \\
\hline $\begin{array}{c}\text { Critical health } \\
\text { literacy }\end{array}$ & 25.3 & 9.1 & 30.6 & 5 & 6.2 & $<0.001$ \\
\hline Total health literacy & 50.8 & 13.6 & 69.3 & 8.9 & 16.2 & $<0.001$ \\
\hline
\end{tabular}

Table 1: Comparison of prior health literacy and after joining the program.

Comparison of attitude and self-care practice before and after participating in the program found that the participants in the program had better attitude and self-care practice, as shown in Table $\mathbf{2}$ and Table $\mathbf{3}$.

\begin{tabular}{|c|c|c|c|c|c|c|c|}
\hline \multicolumn{2}{|c|}{$\begin{array}{c}\text { Attitudes before joining } \\
\text { program }\end{array}$} & \multicolumn{2}{c|}{$\begin{array}{c}\text { Attitudes after joining } \\
\text { program }\end{array}$} & \multicolumn{2}{c|}{$\begin{array}{c}\text { Comparison of attitudes before and after } \\
\text { joining program }\end{array}$} & Same \\
Good & Fair & Bad & Good & Fair & Better & No. $(\%)$ & p-value \\
No. $(\%)$ & No. $(\%)$ & No. $(\%)$ & No. $(\%)$ & No. $(\%)$ & $(\%)$ & 2 & \\
\hline 14 & 12 & 5 & 25 & 6 & 29 & $(6.5)$ & $<0.001$ \\
$(45.2)$ & $(38.7)$ & $(16.1)$ & $(80.6)$ & $(19.4)$ & $(93.5)$ & & \\
\hline
\end{tabular}

Table 2: Comparison of prior attitudes and after joining the program.

\begin{tabular}{|c|c|c|c|c|c|c|c|}
\hline \multicolumn{3}{|c|}{$\begin{array}{c}\text { Self-care practices before } \\
\text { joining program }\end{array}$} & \multicolumn{2}{|c|}{$\begin{array}{c}\text { Self-care practices after } \\
\text { joining program }\end{array}$} & \multicolumn{2}{|c|}{$\begin{array}{c}\text { Comparison of Self-care practices } \\
\text { before and } \\
\text { after joining program } \\
\end{array}$} & \multirow[b]{2}{*}{ p-value } \\
\hline $\begin{array}{c}\text { Good } \\
\text { No. }(\%)\end{array}$ & $\begin{array}{c}\text { Fair } \\
\text { No. }(\%)\end{array}$ & $\begin{array}{l}\text { Bad } \\
\text { No. } \\
(\%) \\
\end{array}$ & $\begin{array}{c}\text { Good } \\
\text { No. }(\%) \\
\end{array}$ & $\begin{array}{c}\text { Fair } \\
\text { No. }(\%)\end{array}$ & $\begin{array}{c}\text { Better } \\
\text { No. }(\%) \\
\end{array}$ & $\begin{array}{c}\text { Same } \\
\text { No. }(\%) \\
\end{array}$ & \\
\hline $\begin{array}{c}15 \\
(48.4)\end{array}$ & $\begin{array}{c}11 \\
(35.5)\end{array}$ & $\begin{array}{c}5 \\
(16.1)\end{array}$ & $\begin{array}{c}25 \\
(80.6)\end{array}$ & $\begin{array}{c}6 \\
(19.4)\end{array}$ & $\begin{array}{c}28 \\
(90.3)\end{array}$ & $\begin{array}{c}3 \\
(9.7)\end{array}$ & $<0.001$ \\
\hline
\end{tabular}

Table 3: Comparison of prior self-care practices and after joining the program.

The participants satisfied this self-care program at highest level as showed in Table 4. 


\begin{tabular}{|c|c|c|c|}
\hline Issue & Mean & SD & Level \\
\hline Suitable Content & 4.62 & 0.36 & Highest \\
\hline Useful content & 4.65 & 0.32 & Highest \\
\hline Easy application & 4.67 & 0.31 & Highest \\
\hline Easy to understand & 4.61 & 0.37 & Highest \\
\hline Facilitator & 4.68 & 0.3 & Highest \\
\hline Time & 4.59 & 0.37 & Highest \\
\hline Convenient & 4.6 & 0.35 & Highest \\
\hline Media & 4.65 & 0.3 & Highest \\
\hline
\end{tabular}

Table 4: Satisfactions on self-care program of participants.

\section{Discussion}

This research aims to promote self-care of HT and DM patients via social media by changing attitude and practice together with health literacy enhancement. The researcher has synthesized the process of transformative learning, which consists of disoriented dilemma, critical reflection on selfexamination with reasons and feelings of fear, anger, guilt, or embarrassment, assessment of assumptions and important relationships, perceptions of others' dissatisfaction and the process of change is shared with others new roles, dialogue or discourse in content, process and premise reflection, propose and accept new perspective to change personal, organizational and social perspective. This synthesized transformative learning process based on experience, holistic orientation, awareness of context and authentic relationship and practice. The researcher starts with creating a crisis artificial or stimulating events because participants in this research change their attitudes towards prevention before the crisis occurs. Crisis is cardiovascular disease, therefore analyzed and synthesized events that may occur if the behavior is a risk factor of heart disease and blood vessels such as paralysis from blood in the brain or heart blockage and loss of leg from distal vein thrombosis and obesity in activity from obesity. These create motivation that is a key component that makes participants begin to change attitudes and behavior according to principle of transformative learning. Health literacy enhancement by using activities such as pretending to be a paralyzed person. From the use of such activities can encourage participants to have awareness of the difficulties of cardiovascular disease well Fostering new attitudes with the use of social media is convenient and able to share of ideas and reflect the idea very well. Program development using the concept of transformative learning in attitude adjustments can be applied in health promotion activities to create awareness for better practice relevant to the study of Niyomtham (2015) which explained that educational activities based on transformative learning can change attitude and consistent with the study of Danit, et al. (2009), which described that health promotion program by changing attitude can lead to good health results. Health promotion process to enhance health literacy focused on critical reflection drives decisionmaking to change attitudes and behavior is consistent with the study of Trezona, et al (2018) and the study of Ngasangsai, et al (2014). Social media use in this research is convenient and continuous to stimulate the participants to have new attitudes to remain consistent with research of Kheokaew, et al (2017), which showed that social media uses lead to increase information and health literacy. From the completion of the program, it was found that after attending the health promotion program participants were more health literacy, good attitudes and self-care practices than before participated in statistically significant activities ( $p$-value $<0.05)$ consistent with (Kitchenham, 2008), which demonstrated that applying the transformative learning theory to health services will provide opportunities for learners to connecting new knowledge and change attitudes and practices. Recommendations from this research are 1) Health promoting program in lifestyle diseases should consider implementing the activities with the principles of transformative learning used to raise awareness, change attitude and behavior to good behavior. 2) Health promotion program should consider using social media to foster, increase accessibility and reflection.

Acknowledgement: This research was supported by Thailand Research Funded (TRF).

\section{References}

1. Aekplakorn W et al. (2020) Prevalence of Diabetes and Relationship with Socioeconomic Status in the Thai Population: National Health Examination Survey, 20152019. Journal of Diabetes Research.1-9.

2. Alharbi M, Gallagher R, Kirkness A, Sibbritt D, Tofler G (2016) Long-term outcomes from Healthy Eating and Exercise Lifestyle Program for overweight people with heart disease and diabetes. Eur J Cardiovasc Nurs. 15:9199.

3. Antonacopoulou E, Gabriel Y (2001) Emotion, learning and organizational change: Towards an integration of psychoanalytic and other perspectives. Journal of Organizational Change Management. 34:67-74.

4. Beck J et al. (2017) Standards Revision Task Force National standards for diabetes self-management education and support. Diabetes Care. 40:1409-1419.

5. Boyd RD, Meyers JG (1988) Transformative Education. International Journal of Lifelong Education. 7:261-284.

6. Cesar CJ (2003) Adult motivation to complete their baccalaureate degree. Graduate School of Education and Psychology. Malibu CA, Pepperdine University.

7. Cooperrider D, Whitney D (2000) The appreciative inquiry summit: An emerging methodology for whole system change. OD Practitioner. 32:13-26.

8. Cranton P (1996) Professional development as transformative learning: New perspectives for teachers of adults. San Francisco: Jossey-Bass. 
9. Cranton $P$ (2006) Fostering authentic relationships in the transformative classroom. New Directions for Adult and Continuing Education. 109:5-13.

10. Curtis K (2017) Using Appreciative Inquiry to develop, implement and evaluate a multi-organization 'Cultivating Compassion' programme for health professionals and support staff. Journal of Research in Nursing. 22:150-165.

11. Danit et al. (2009) A controlled intervention study of changing health-providers' attitudes toward personal lifestyle habits and health-promotion skills. Nutrition. 25:532-539.

12. De Fronzo RA (2010) Current issues in the treatment of type 2 diabetes. Overview of newer agents: where treatment is going. Am J Med. 123 (3 Suppl):38-48.

13. Dirkx J (1998) Transformative Learning Theory in the Practice of Adult Education: An Overview. PAACE Journal of Lifelong Learning. 7:1-14.

14. Dirkx J (2000) Transformative Learning and the Journey of Individuation. ERIC Digests. 223:65-72.

15. Dirkx J (2001) The power of feelings: Emotion, imagination, and the construction of meaning in adult learning. New Directions for Adult and Continuing Education. 89:63-72.

16. Dirkx J (2006) Studying the Complicated Matter of What Works: Evidence-Based Research and the Problem of Practice. Adult Education Quarterly, 56:273-290.

17. Fisher EB et al. (2017) Peer support of complex health behaviors in prevention and disease management with special reference to diabetes: systematic reviews. Clin Diabetes Endocrinol. 3:89-96.

18. Fook J, Askeland G (2007) Challenges of critical reflection: 'Nothing ventured, nothing gained'. Social Work Education. 26:520-533.

19. Grady PA, Gough LL (2014) Self-management a comprehensive approach to management of chronic conditions. Am J Public Health. 104:25-31.

20. Harvie PLB (2004) Transformative learning in undergraduate education. Toronto: University of Toronto.

21. Hung L et al. (2018) Appreciative Inquiry: Bridging Research and Practice in a Hospital Setting. International Journal of Qualitative Methods. 17:1-10.

22. Illeris $\mathrm{K}$ (2004) Transformative Learning in the Perspective of a Comprehensive Learning Theory. Journal of Transformative Education. 2:79-89.

23. Kheokao J et al. (2017) Online social media uses and eHealth literacy of Cambodian workers in Thailand. TLA Research Journal. 10:33-46.

24. Kitchenham A (2008) Building on Mezirow's Theory of Transformative Learning: Theorizing the Challenges to Reflection. Journal of Transformative Education. 6:155164.

25. Lange E (2004) Transformative and Restorative Learning: A Vital Dialectic for Sustainable Societies. Adult Education Quarterly. 54:121-139.

26. Lauckner H, Hutchinson SL (2016) Peer support for people with chronic conditions in rural areas: a scoping review. Rural Remote Health. 16:36-41.

27. Lytle JE (1989) The process of perspective transformation experienced by the registered nurse returning for baccalaureate study. Unpublished doctoral dissertation, Northern Illinois University, Dekalb.
28. McWilliam A et al. (1999) Creating empowering meaning: An interactive process of promoting health with chronically ill older Canadians. Health Promotion International. 2:58-63.

29. Merriam SB (2004) The Role of Cognitive Development in Mezirow's Transformational Learning Theory. Adult Education Quarterly. 55:60-68.

30. Mezirow J (1991) Transformative Dimensions of Adult Learning. Jossey-Bass: San Francisco, CA.

31. Mezirow J (2000) Learning to think like an adult. SanFrancisco, CA: Jossey-Bass.

32. Ministry of Public Health Thailand. (2020). Annual Health Report 2019. Nontburi: Ministry of Public Health Publishing.

33. Ngasangsai P et al. (2014) A Case Study of Health Literacy of Village Health Volunteers. Journal of Pharmaceutical Science. 9 (Supplement):82-87.

34. Niyomtham O (2016) The Development of Curriculum to Enhance Loving-Kindness and Compassion through Transformative Learning Theory. Academic Journal of Humanities and Social Sciences Burapha University. 23:273-290.

35. O'Sullivan E (1999) Transformative Learning: Educational Vision for the 21st Century. London: Zed Books.

36. Partridge SR et al. (2017) Cardiac patients' experiences and perceptions of social media: mixed-methods study. J Med Internet Res. 19:32-39.

37. Peters AE, Keeley EC (2017) Patient engagement following acute myocardial infarction and its influence on outcomes. Am J Cardiol. 20:1467-1471.

38. Riegel B, et al. (2017) American Heart Association Council on Cardiovascular and Stroke Nursing; Council on Peripheral Vascular Disease;Council on Quality of Care and Outcomes Research Self-care for the prevention and management of cardiovascular disease and stroke: a scientific statement for healthcare professionals from The American Heart Association. J Am Heart Assoc. 6:23-32.

39. Santarossa S, Kane D, Senn CY, Woodruff SJ (2018) Exploring the role of in-person components for online health behavior change interventions: can a digital person-to-person component suffice? J Med Internet Res. 20:14-24.

40. Scerri A, Innes A, Scerri C (2019) Using appreciative inquiry to implement person-centred dementia care in hospital wards. Dementia. 18:190-209.

41. Scott SM (2003) The social construction of transformation. Journal of Transformative Education. $1: 264-284$.

42. Smailhodzic E, Hooijsma W, Boonstra A, Langley DJ (2016) Social media use in healthcare: a systematic review of effects on patients and on their relationship with healthcare professionals. BMC Health Serv Res. 16:3442.

43. Swerisssen H, Crisp B (2004) The sustainability of health promotion interventions for different level of social organization. Health Promotion International.19:27-35.

44. Taylor EW (1993) A Learning Model of Becoming Interculturally Competent: A Transformative Process. Unpublished dissertation: University of Georgia. 
45. Taylor EW (1998) Transformative Learning: A Critical Review. ERIC Clearinghouse on Adult, Career, and Vocational Education. 374:356-362.

46. Taylor EW (2003) Attending Graduate School in Adult Education and the Impact on Teaching Beliefs: A Longitudinal Study. Journal of Transformative Education, 1:349-368.

47. Taylor EW (2009) Fostering transformative learning. In J Mezirow \& EW Taylor (Eds.), Transformative learning in practice: Insights from community, workplace, and higher education, 3-17. San Francisco: Jossey-Bass.

48. Tennant MC (1991) The Psychology of Adult Teaching and Learning. In JM Peters and P Jarvis and Associate (eds.), Adult Education: Evolution and Achievements in a Developing Field of Study. San Francisco: Jossey-Bass.

49. Trajkovski et al. (2015) Using appreciative inquiry to bring neonatal nurses and parents together to enhance family-centred care: A collaborative workshop. J Child Health Care, 19:239-253.
50. Trezona et al. (2018). Development of the Organisational Health Literacy Responsiveness (Org-HLR) selfassessment tool and process. BMC Health Services Research, 3:99-105.

51. Wasserman IC (2009). Innovations in Transformative Learning: Space, Culture, \& the Arts. JSTOR. 341:321320.

52. Willis CD et al. (2016) Sustaining organizational culture change in health systems. Journal of Health Organization and Managemen, 30:2-30.

53. World Health Organization. (2018) Diabetes. On October, 10, 2019.

54. Yach D, Leeder SR, Bell J, Kistnasamy B (2005) Global chronic diseases. Science, 21:307-317.

55. Yorks L, Kasl E (2002) Toward a theory and practice for whole-person learning: reconceptualizing experience and the role of affect. Adult Education Quarterly, 52:176-192.

56. Yu OH, Suissa S (2016) Identifying causes for excess mortality in patients with diabetes: closer but not there yet. Diabetes Care, 39:1851-1853.

Citation: Prasak santiparp (2021) Health Promotion Program via Social Media for Hypertension and Diabetes Mellitus Patients. Adv Pub Health Com Trop Med: APCTM-131. 